\title{
STIMULUS ENTREPRENEURSHIP BERBASIS GAME PADA SISWA SEKOLAH MENENGAH PERTAMA ISLAM MANBAUL ULUM GRESIK
}

\author{
Anisah Firdausiah Oktarilivyana \\ Universitas Internasional Semen Indonesia, \\ email : anisah.oktarilivyana@gmail.com \\ Bunga Brylline Putri Suharto \\ Universitas Internasional Semen Indonesia \\ Juliana Kristi \\ Universitas Internasional Semen Indonesia \\ Bayu Alfiansyah \\ Universitas Internasional Semen Indonesia \\ Alferdo Doni Fadlillah \\ Universitas Internasional Semen Indonesia \\ Ngatini, S.Si., M.Si. \\ Universitas Internasional Semen Indonesia

\section{Abstrak}

SMP Islam Manbaul Ulum memiliki beberapa kegiatan ekstrakurikuler untuk mendukung siswanya dalam mengembangkan potensi atau minat dan bakat. Tidak terkecuali ekstrakurikuler kewirausahaan. Sejauh ini pengembangan program ekstrakurikuler kewirausahaan masih belum optimal karena metode pelaksanaannya terlalu monoton dengan hanya memberikan arahanarahan tanpa memberikan kesempatan atau peluang secara langsung kepada siswa-siswi untuk merasakan atsmosfer bisnis. Millennipreneur hadir dengan mengusung konsep yang lebih terukur dan terarah. Menggunakan metode DIPEV (Discuss, Implementation, Product Expo, Evaluasi), Millennipreneur memberikan pembelajaran kewirausahaan yang menyenangkan melalui Game Android. Siswa-siswi lebih mampu menangkap pembelajaran kewirausahaan dengan melakukan simulasi bisnis yang ada pada game Millennipreneur untuk kemudian direalisasikan sebagaimana proses bisnis pada umumnya. Terbukti dengan metode ini, mampu menjadi stimulus bagi siswa-siswi SMP Islam Manbaul Ulum untuk tertarik pada bidang kewirausahaan.

Kata Kunci: bisnis, kewirausahaan, game, smartphone.

\section{Abstract}

Manbaul Ulum Islamic Middle School has several extracurricular activities to support students in developing their potential or interests and talents. Entrepreneurship extracurricular is no exception. So far the development of entrepreneurial extracurricular programs is still not optimal because the method of implementation is too monotonous by only providing directives without providing opportunities or opportunities directly to students to feel the business atmosphere. Millennipreneur comes with a more measurable and directed concept. Using the DIPEV method (Discuss, Implementation, Product Expo, Evaluation), Millennipreneur provides 
fun entrepreneurial learning through the Android Game. Students are better able to capture entrepreneurial learning by conducting business simulations in the Millennipreneur game to then be realized as business processes in general. Evidenced by this method, it can be a stimulus for students of Manbaul Ulum Islamic Middle School to be interested in the field of entrepreneurship.

Keywords: business, entrepreneur, game, smarthphone.

\section{PENDAHULUAN}

Sekolah Menengah Pertama (SMP) merupakan pendidikan formal pada jenjang pendidikan dasar yang ditempuh selama 3 tahun mulai dari kelas 7 sampai kelas 9 (Wikipedia, 2018). Pendidikan dan pembelajaran di tingkat SMP memberikan penekanan peletakan pondasi dalam menyiapkan generasi agar menjadi sumber daya manusia yang mampu menghadapi era yang semakin berat.

SMP Islam Manbaul Ulum Gresik didirikan atas inisiatif direktur utama PT Semen Gresik (Semen Indonesia, (Persero) Tbk) oleh Bapak Ir. Anang Fuad Rifa'i. Sekolah tersebut menerapkan pengembangan potensi pada siswanya. Hal ini dilakukan oleh pihak sekolah untuk kesiapan siswanya dalam memilih sekolah lanjutan atau dunia pekerjaan. Berdasarkan hasil observasi dan hasil kuesioner yang dibagikan kepada siswa, hanya $40 \%$ siswa SMP Islam Manbaul Ulum Gresik yang memahami potensi dalam dirinya sehingga mampu dituangkan dalam kegiatan ekstrakurikuler. Pemahaman potensi diri merupakan dasar dalam pengambilan pilihan dan keputusan peserta didik dalam bidang keahlian (Kusri, 2016).Kurangnya pemahaman tenaga pendidik akan potensi siswanya, menyebabkan siswa tidak maksimal dalam pencarian jati diri.

Salah satu upaya yang sudah dilakukan oleh SMP Islam Manbaul Ulum Gresik adalah dengan memberikan form minat dan bakat serta mengadakan pelatihan camp dalam waktu 2 hari bagi siswa baru guna menumbuhkan potensi siswa yang nantinya akan dilanjutkan melalui ekstrakurikuler selama kegiatan di sekolah. Penilaian ekstrakurikuler ini masuk ke dalam penilaian rapot siswa. Selain itu, SMP Islam Manbaul Ulum juga memiliki program sekolah mengenai kewirausahaan dengan kegiatan bank sampah untuk tetap menumbuhkan peran siswa dalam peduli lingkungan sekaligus mendapatkan dana yang digunakan siswa dalam berbagai kegiatan- kegiatan.

Beberapa upaya tersebut ternyata tidak dapat menjadi solusi yang optimal. Tenaga pendidik masih merasa kesulitan 
untuk memahami potensi dari siswa. Pihak sekolah telah melakukan komunikasi dengan pihak orang tua siswa untuk mengarahkan anaknya mengikuti kegiatan sekolah. Berdasarkan hasil observasi dan hasil kuesioner yang dibagikan kepada siswa dari 157 siswa kelas 7 dan 142 siswa kelas 8, 70\% siswa justru mengalihkan minatnya untuk bermain game online dan $20 \%$ memiliki bisnis online.

Melihat kenyataan di atas, penulis tertarik untuk melakukan Pengabdian Kepada Masyarakat dalam sebuah game online berbasis game kewirausahaan/entrepreneur

(Millennipreneur) yang diharapkan mampu memberikan solusi kepada SMP Islam Manbaul Ulum Gresik untuk memudahkan dalam memahami, meningkatkan serta mengembangkan potensi siswanya dalam entrepreneur. Entrepreneur mempunyai peranan yang sangat penting yakni dapat mengubah hidup terbawah penduduk dunia dan menolong mereka keluar dari masalah perekonomian yang kurang. Ekonomi suatu bangsa akan meningkat ketika minat entrepreneurship masyarakat cukup tinggi. Entrepreneur dapat mendorong siswa untuk mendalami sesuatu yang mereka minati dan untuk mengarah pada tindakan-tindakan real mengarah dan berorientasi terhadap entrepreneurship (Jhonij Sugiarto, 2015). Realitas semacam ini menjadi perhatian bagi penulis sebagai masyarakat yang sadar akan peran penting dari menanamkan minat entrepreneurship sejak dini. Game Millennipreneur dilengkapi dengan fitur- fitur yang berhubungan dengan manajemen dunia bisnis. Dalam kegiatan Millennipreneur, terdapat kegiatan yang menunjang untuk pengaplikasiannya dalam dunia nyata yakni berupa metode "DIPEV" (Discuss, Implementation, Product Expo and Evaluation). Implementasi di SMP Islam Manbaul Ulum Gresik ini nantinya diharapkan mampu menjadi "pilot project $^{\text {“ }}$ untuk sekolah- sekolah di sekitarnya.

\section{GAMBARAN}

\section{UMUM}

\section{MASYARAKAT SASARAN}

Masyarakat sasaran dalam pengabdian ini adalah SMP Islam Manbal Ulum Gresik yang terletak di Jalan Sunan Giri VII/23, Kawisanyar, Kecamatan Kebomas, Kabupaten Gresik, Jawa Timur dengan memiliki luas lahan sebesar $1.200 \mathrm{~m}^{2}$. Dibawah pimpinan Ibu Fzuziyah Mufidah dengan jumlah siswa 479 siswa, siswa laki- laki sebanyak 305 siswa dan siswa perempuan sebanyak 
174 siswa. Kemudian tenaga pengajar di

SMP Islam Manbaul Ulum sebanyak 32 guru (Sumber: Data Center SMP Islam Manbaul Ulum, 2018).

SMP Islam Manbaul Ulum memiliki beberapa kegiatan ekstrakurikuler untuk mendukung siswanya dalam mengembang potensi atau minat dan bakat. Dengan memberikan formulir minat dan bakat serta mengadakan pelatihan camp dalam waktu 2 hari bagi siswa baru guna menumbuhkan potensi siswa yang nantinya akan dilanjutkan melalui ekstrakurikuler selama kegiatan di sekolah.

Namun kurangnya pemahaman tenaga pendidik akan potensi siswanya menyebabkan hanya beberapa siswa yang memahami potensi masing-masing dan dituangkan ke dalam kegiatan ekstrakulikuler dan tidak banyak dari siswa memahami tentang entrepreneurship sehingga perlu ditanamkan sejak dini potensi menjadi entrepreneur kepada generasi penerus bangsa.

\section{METODE}

Metode yang digunakan dalam melaksanakan kegiatan pengabdian masyarakat ini adalah sebagai berikut :

\section{Komunikasi/Negosisasi dengan Mitra}

Pada proses ini, penulis melakukan pembahasan mengenai program Business Game Simulator yang akan dibuat dan rencana implementasinya.

\section{Pembuatan Game}

Pada proses ini, penulis mulai membuat program Business Game Simulator menggunakan bahasa pemrograman Java yang disesuaikan dengan konsep dan desain yang telah dibuat.

\section{Trial Game}

Pada proses ini, penulis menguji kelayakan dan kinerja program untuk memastikan kestabilan program.

\section{Sosialisasi}

Pada proses ini, penulis melakukan proses pengenalan Millennipreneur pada siswa-siswi SMP Manbaul Ulum Gresik. Sosialisasi dilakukan melalui pertemuan pada program ekstrakurikuler kewirausahaan yang dibuat oleh sekolah selama 1 hari. Pada hari tersebut diadakan publikasi ilmiah, yang mengarah pada sistem pembelajaran berbasis game simulator untuk siswa-siswi SMP Manbaul Ulum Gresik yang kemudian dilanjutkan pelatihan mengenai penggunaan Millennipreneur sebagai media pembelajaran. 


\section{Implementasi}

Pada proses ini, penulis memulai untuk mengimplementasikan Millennipreneur kapada siswa-siswi yang diawali dengan menginstal software game tersebut pada setiap gadget siswa-siswi SMP Manbaul Ulum Gresik.

\section{Pengembangan Selanjutnya}

Pada proses ini, penulis akan menggunakan metode "DIPEV" sebagai bentuk kelangsungan program pembelajaran sebagaimana terlihat pada Gambar1 berikut ini :

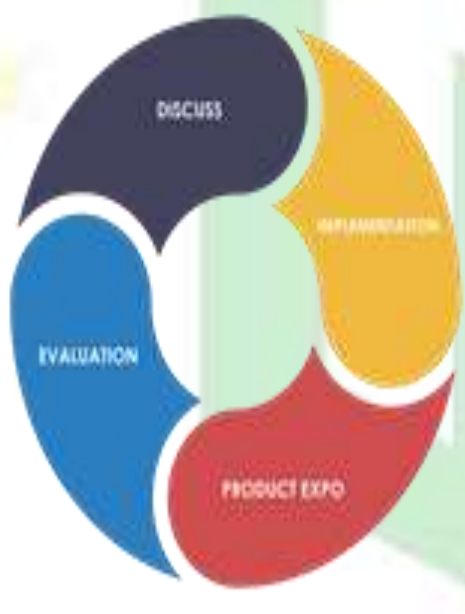

Gambar 1. Metode "DIPEV"

a. Discuss (Dilakukan untuk memberi edukasi kepada siswa-siswi untuk menjalankan bisnis dengan memperhitungkan beberapa hal untuk mencapai profit yang maksimum.)

b. Implementation (Dilakukan untuk memberi pengalaman berbisnis kepada siswa-siswi dengan membuat bisnis nyata sesuai dengan bisnis yang telah dijalankan dalam game simulator.)

c. Product Expo (Dilakukan untuk memberikan pembelajaran kepada siswa-siswi untuk mengenalkan produk yang telah mereka buat kepada masyarakat umum sebagai salah satu upaya pemasaran produk.)

d. Evaluation (Dilakukan untuk mengontrol aktifitas bisnis yang telah dilakukan siswa-siswi sebagai referensi dan panduan dalam menjalankan bisnis yang selanjutnya).

\section{HASIL DAN PEMBAHASAN}

Business Game Simulator yang dikembangkan diberi nama “Millenipreneur". Game ini diakses oleh siswa SMP Manbaul Ulum Gresik menggunakan smartphone pribadi mereka. dengan konsep cara berbisnis jus dengan melihat dari strategi yang dihasilkan agar pemain mendapatkan profit sebanyak-banyaknya. Berikut adalah tampilan aplikasi game Millenipreneur : 


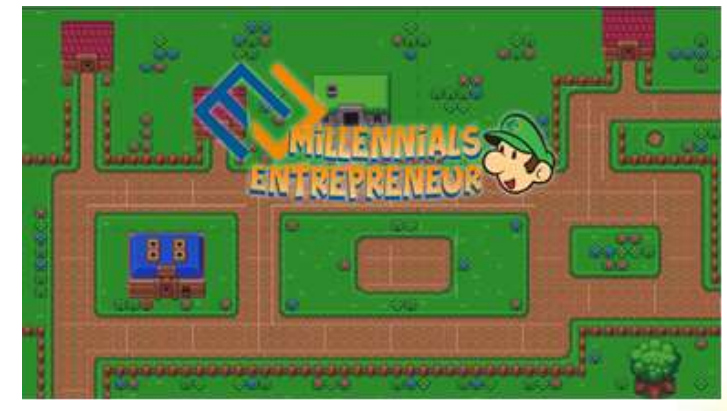

Gambar 2. Game Millennipreneur

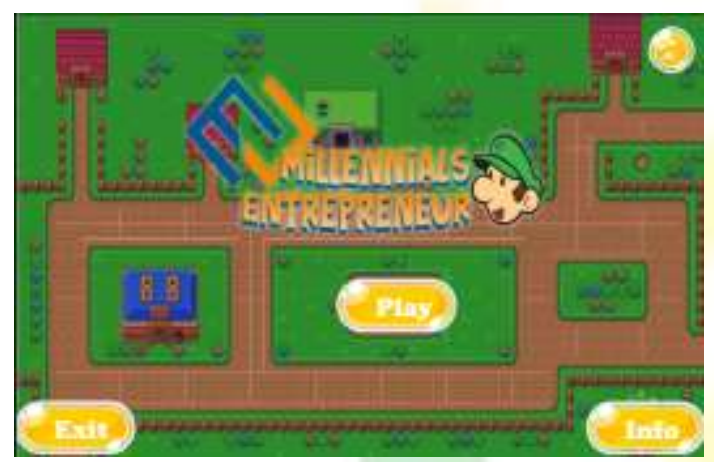

Gambar 3. Main Menu Game Millennipreneur

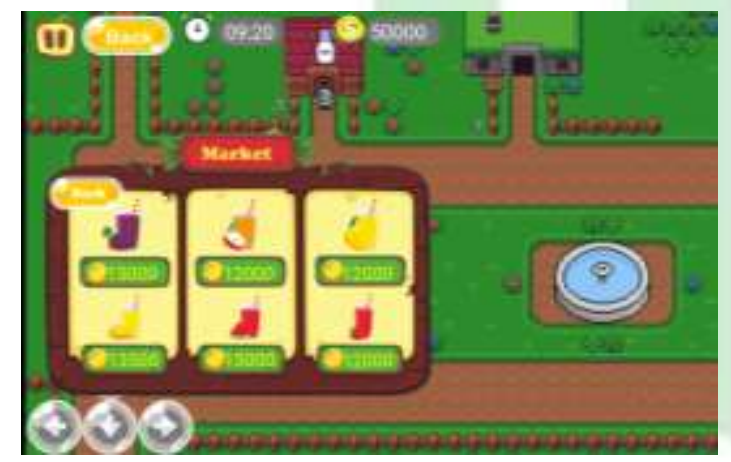

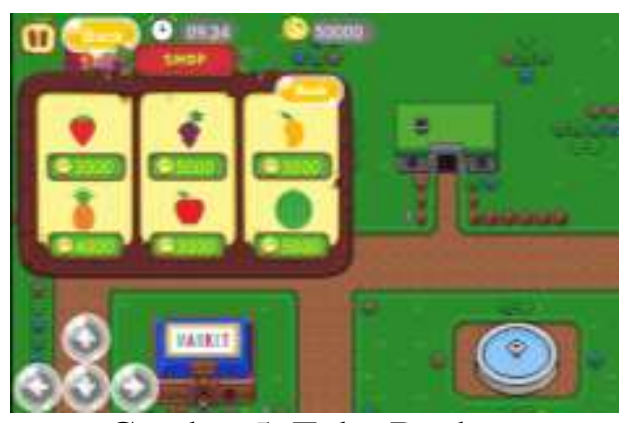

Gambar 5. Toko Buah

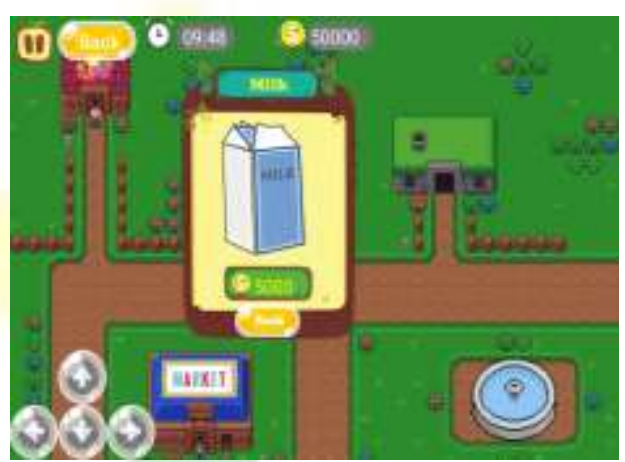

Gambar 6. Toko Susu

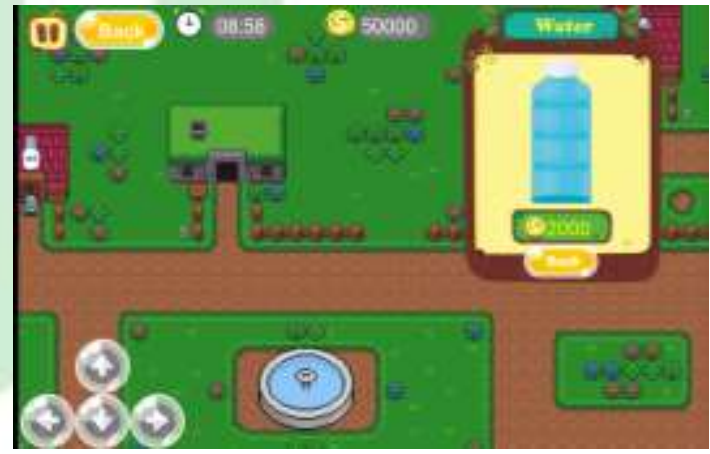

Gambar 7. Toko Air

Gambar 4. Daftar Harga Jual Jus 


\section{KESIMPULAN}

Kesimpulan dari serangkaian kegiatan pengabdian masyarakat ini adalah sebagai berikut :

1. Stimulus entrepreneurship berbasis game diberi nama Millennipreneur

2. Game Millennipreneur telah diimplementasikan pada siswa SMP Manbaul Ulum Gresik.

3. Game Millennipreneur memberikan pemahaman siswa terhadap entrepreneurship mulai dari tata cara riset pasar sampai dengan tahap penjualan.

\section{REFERENSI}

Jhonij Sugiarto, Y. B. W. d. C. T. U., 2015. Efektivitas Pelatihan Entrepreneurship Skill Untuk Meningkatkan Minat Menjadi Entrepreneur. Kajian Ilmiah Psikologi, pp. 51-60.

Kusri, A. M., 2016. Pengaruh Layanan Informasi Peminatan Terhadap. Jurnal Psikologi Pendidikan \& Konseling, 28 Juni, Volume 2, pp. 49-57.

Wikipedia, 2018. Sekolah menengah pertama.

[Online]

Available at: https://id.wikipedia.org/wiki/Sekola h_menengah_pertama 